\title{
LATENT STRUCTURE OF BELIEFS ABOUT MEN'S AND WOMEN'S EMOTIONAL BEHAVIOUR IN A SAMPLE OF SERBIAN STUDENTS
}

\author{
UDC 159.942.072:316.7 + 159.942-055.11.2
}

\section{Marija Pejičić, Nikola Ćirović}

University of Niš, Faculty of Philosophy, Department of Psychology

\begin{abstract}
Rules regarding emotional display (and hence, regulation) are provided by society in order to guide gender-specific or gender appropriate behaviour of the individual. The purpose of this research was the adaptation of the Questionnaire of gender specific beliefs about emotional behaviour (Timmers, Fischer, \& Manstead, 2003), supplemented with additional items, on a sample of 247 Serbian students. A large set of observed beliefs about actual or desired emotional conduct in the context of separate male and female gender roles was subjected to sequential-factors analysis (Goldberg's "bass-ackwards" method). The aim was to elucidate specific homogenous clusters of beliefs (factors) and their larger contexts (higher-level factors), therefore providing information on the societal views of gender roles and also on the potentially differing cross-cultural manifestations of the constructs in question. Finally, two measurement instruments were evaluated and suggested for future research. The psychometric properties of these instruments, the Beliefs about men's emotional behaviour (BEB-M) and the Beliefs about women's emotional behaviour (BEB-W), were assessed. Based on interpretability, as well as on the results of a parallel analysis and the MAP procedure, we made the decision to use a four-factor solution for the BEB-M instrument, and a fivefactor solution for the BEB-W instrument.
\end{abstract}

Key words: gender roles, emotional behaviour, latent structure, sequential-factors, cross-cultural adaptation

\section{INTRODUCTION}

During the process of socialisation, an individual acquires socially relevant forms of behaviour and is formed as a personality with his/her specific characteristics (Rot 2008). Hofstede, Hofstede, \& Minkov (2010) speak about patterns according to which an individual thinks, feels and acts ("software of the mind"; Hofstede et al. 2010, 5), and

Received March 27, 2019 / Accepted July 16, 2019

Corresponding author: Marija Pejičić

University of Niš, Faculty of Philosophy, Ćirila i Metodija 2, 18000 Niš, Serbia

E-mail: marija.pejicic@ filfak.ni.ac.rs 
which he/she acquires through experience within a certain social environment. According to these authors, culture is one form of "mental software". When it comes to gender roles, they point out that, despite variations among cultures, there are certain traits that are predominantly ascribed to women or men respectively. In that way, self-confidence, competitiveness and strength are considered desirable masculine traits, and gentleness, sensibility, caring and humbleness are considered feminine.

Based on the analysis of empirical data, certain authors (Timmers, Fischer, \& Manstead 2003) conclude that the emotions of men and women adhere to different norms of expression in each culture. Therefore, women, who are considered more emotional than men, are "permitted" by culture to express positive emotions, and not negative ones which can hurt others. The results of earlier studies generally confirm gender stereotypes related to emotional behaviour (Hess, Senecal, Kirouac, Herrera, Philippot, \& Kleck 2000; Plant, Hyde, Keltner, \& Devine 2000). These studies confirmed the existence of beliefs that women exhibited emotions such as joy, shame, surprise, fear, shame and guilt, while men exhibited anger, repulsion and pride, in accordance with the norms that they acquired from their respective cultures. So, social norms shape what the members of certain society could expect in the behaviour of others, and, along with that, shape the way they perceive the behaviour of other members of society. In a study by Timmers et al. (2003), on a sample of Dutch students, men were viewed as less emotional, but also as the ones who prefer power to a greater degree, and in keeping with that, the ones who express emotions with which they demonstrate power (e.g. anger). On the other hand, the respondents deemed expressions of negative emotions that indicate weakness or impotence non-desirable. That same research concluded that expressions of emotions were deemed less functional in cases where women were expressing them, as opposed to cases where men were doing the same. The authors of the study concluded that attitudes towards emotions manifested by men were more positive and generally nonstereotypical, in contrast with attitudes concerning women, and consequently, men were deemed more competent owing to their greater emotional sensitivity. However, there was another study, by the same authors, in which the respondents measured the desirability of their own emotional behaviour, and the aforementioned gender differences related to the manifestation of emotions expressing inability, as well as the level of emotional sensitivity, disappeared.

Further studies confirmed that the stereotype of a strong male is reflected in both expectations placed on a child and in a child's upbringing (Casey \& Fuller 1994). It was discovered that mothers of girls, aged three and seven, to a lesser degree regulate the manifestation of anger than mothers of boys of the same age, while the tendency was reversed with mothers of children aged five and nine. Based on the data that mothers to a higher degree react to two-year-old boys' crying than to two-year-old girls' crying, other authors (Brooks-Gunn \& Lewis 1982, according to Oatley \& Jenkins 1998) concluded that mothers, in that way, send the message about the non-acceptance of the manifestation of sadness among boys. In a longitudinal study, which was carried out two decades later, this conclusion found its confirmation. In that research, the expression of boys and girls, aged four and six, was measured at the facial, vocal and postural levels. It was confirmed that girls show sadness and anxiety to a greater degree, and that the expressiveness of boys decreased over a period of two years (Chaplin, Cole, \& Zahn-Waxler 2005). The results of these studies point to the parents' aspiration to teach boys, through the process of socialisation, to suppress their feelings, primarily fear, anger and sadness. A self-fulfilling prophecy could be one of the mechanisms through which stereotypes achieve their effects 
on targets of stereotype (Baumeister \& Bushman 2010). People often behave in accordance with the expectations of society, partly due to the way its members treat them, which is guided by those expectations. In other words, stereotypes could affect actual behaviour of their targets through the fulfilling prophecy, resulting in actions which are congruent with the stereotypes others hold of them.

Belief regarding greater emotionality of women found confirmation in a cross-cultural study with participants from 37 cultures, in which women reported that they expressed emotions, which were greater in intensity and duration, more openly (Fischer \& Manstead 2000). These differences were larger in individualistic cultures, when research was done on emotions such as happiness, shame, disgust, and guilt. In the same vein, one study confirmed the greater expressivity of women during manifestations of happiness and fear (Huang 2009). This is also supported by the data of one meta-analytical study which found that women smile more than men (LaFrance, Hecht, \& Paluck 2003), and the results of the research in which most respondents agreed that women in their surroundings more often express emotions such as fear and sadness, which they use to show their vulnerability (Timmers et al. 2003).

Cross-cultural research, conducted on a sample consisting of respondents from the USA, South Korea, Japan and Russia, has shown that women are mainly focused on controlling emotions such as anger, disgust and spite, while men were mostly focused on fear and surprise (Matsumoto, Takeuchi, Andayani, Kouznetsova, \& Krupp 1998). The results of research, done on gender differences, proved inconclusive and contingent regarding situational factors, sample characteristics and used measuring techniques (Benetti-McQuoid \& Bursik 2005; Ferguson, Eyre, \& Ashbasker 2000). Although it cannot be stated that all the empirical data confirms gender differences in anger manifestation (Huang 2009; Simon \& Nath 2004), some studies indicate that men exhibit heightened facial reactivity when experiencing anger (Dimberg \& Lundquist 1990), which is further supported by the data indicating that respondents identified anger manifestations more easily on male faces, when compared with female faces (Coats \& Feldman 1996).

The authors of this paper have not found any information regarding extensive research on normative, perceived or actual gender differences in emotional expression conducted on a Serbian population. Data exists regarding the importance stressed by students from 48 nations (including Croatia) about the emotional characteristics of their future children, such as happiness, fearlessness, and anger suppression (Diener \& Lucas 2004). Studies have shown that gender is not a factor when it comes to happiness, but that fearlessness is deemed more desirable for male children. This study also uncovered that anger suppression was deemed more desirable for boys rather than girls. Namely, future parents would like their sons to control their anger to a greater degree than their daughters. Diener and Lucas expressed reluctance as to how to interpret this result as it ran contrary to the stereotype of the socially-accepted male aggression. One of their assumptions referred to greater tolerance of different cultures towards expressing emotions by women, compared to their manifestation with men. Another assumption of theirs was that boys are thus taught that they possess more anger, which they should suppress. Male participants considered this characteristic more important, compared to female participants.

However, not all cultures are equally demanding when it comes to abiding by certain norms (Hofstede et al. 2010). Hofstede and his associates recognise in their model indulgence as opposed to restraint, as a dimension of culture. One pole of this dimension, indulgence, was defined as "a tendency to allow relatively free gratification of basic and 
natural human desires related to enjoying life and having fun" (Hofstede et al. 2010, 281). The other pole, restraint, was determined as "a conviction that such gratification needs to be curbed and regulated by strict social norms" (Hofstede et al. 2010, 281). On the sample which was composed of 93 countries, Serbia was closer to the pole of restraint, with an index of 28 (scope $0-100$ ) and a rank of 70-72. In accordance with this, it can be expected that the acceptance of the norms in general, even those referring to the gender role, will be high on the Serbian sample.

Another dimension of culture from the model of Hofstede and his associates (Hofstede et al. 2010) could be significant for gender differences in emotional behaviour. That is the dimension according to which cultures differ in the degree of differentiation of male and female roles. Society can be seen as masculine "when emotional gender roles are clearly distinct: men are supposed to be assertive, tough, and focused on material success, whereas women are supposed to be more modest, tender, and concerned with the quality of life" (Hofstede et al. 2010, 140). On the other hand, certain societies are seen as feminine "when emotional gender roles overlap: both men and women are supposed to be modest, tender, and concerned with the quality of life" (Hofstede et al. 2010, 140). In their study, conducted in 76 countries, Serbia had an index of 43 (scope 0-100), which ranked it between 47 and 50, and placed it on the border between feminine and masculine cultures, although it mildly gravitates towards the feminine.

However, the results of a sociological research (Blagojević Hughson 2013), conducted in 2012 in Serbia, are not consistent with this result. It revealed that a larger percentage of men $(80 \%)$ than women $(67 \%)$ stated that they could count on support from their partners, which means that dealing with emotions is, primarily the women's role. In addition, a larger number of women, in relation to men, believed that children were the meaning of life, that women were overwhelmed with house chores, that decisions in marriage should be made together, and that they give priority to love over money. On the other hand, men more often expressed a positive attitude towards the fact that there was a dominant person within the family, towards the traditional role of a woman as a housewife, but also a negative attitude towards abortion, and placed an emphasis on the importance of money for happiness.

Another study (Mladenović 1991, as cited in Havelka 2012) revealed traits which were preferable for women, as well as those preferable for men. Preferable traits for women are honesty, indulgence, humanity, sensitivity and gentleness, and they are expected to be cute, polite, pleasant, considerate, and conscientious. On the other hand, courage, self-confidence, a strong personality, skillfulness, energy, being adventurous and ability represent traits which make up a positive cultural stereotype of men.

Based on the available data, in our opinion that beliefs about the emotional behaviour of men and women in our region demand additional empirical research. Since those beliefs, by shaping expectations and behaviour, showed a tendency to affect the behaviour of their targets, which in turn confirm those beliefs, we found the examination of those beliefs as important, not only a scientific problem, but also as a problem with practical implications, that will help in raising awareness about the stereotypes and their function in social interactions.

According to this, the aims of the study were as follows:

1. an examination of latent structure of beliefs about men's and women's behaviour in a sample of Serbian students for conceptual purposes - we aimed at drawing inferences about the structure of gender roles and their context (non-psychometric aim);

2. adaptation (re-construction) of the instrument provided in the paper by Timmers et al. (2003) and its further development guided by conceptual reasons (the representativeness of the basic emotional experiences in the item pool). 


\subsection{Questionnaire of gender-specific beliefs about emotional behaviour}

What follows is the detailed description of the procedure we performed in order to develop the version of the instrument that is suitable to our research goals. Firstly, the 54 items were taken from the original instrument (only those that refer to hetero-stereotypical beliefs). Excluded from the instrument were items that Timmers et al. (2003) used in their third study to investigate whether the beliefs and norms manifested in relation to the emotional behaviour of men and women were also reflexively applied to the respondents' own behaviour. The main goal of our paper was to precisely determine the structure of belief pertaining to the emotional reactions of men and women, as well as checking whether possible differences in the manifestations of the construct underlying observed variables exist when items designed to measure beliefs regarding male emotional behaviour are compared with those measuring female emotional behaviour.

Timmers et al. (2003) utilized a subtle-blatant prejudice distinction, outlined in the works of Pettigrew and Meertens (1995) during item construction, classifying beliefs as either prescriptive or descriptive, whereby prescriptive items are seen as more directly provoking an individual's beliefs. Besides the subtle-blatant item distinction, based on theoretical grounds, authors of this instrument also classify items according to whether they measure beliefs about manifestations of powerful or powerless emotions, with a man or woman as a target. According to those criteria, all items could be classified as prescriptive stereotypical and descriptive stereotypical items. Prescriptive items contain stereotypical normative beliefs regarding the emotional behaviour of women (e.g. Women should not be aggressive) and men (e.g. Men should not show their sadness). Agreement with the items pointed to the endorsement of the belief that men are allowed to manifest strength, while women weakness. With regards to descriptive items, they are grouped according to an additional criterion - that of the content of emotional behaviour (its form or the context in which it occurs), or, according to the authors, they are based on face-validity grounds. Therefore, descriptive items brought to light stereotypes concerning the emotional behaviour of men and women in a more subtle way, through the level of agreement with items concerning specific aspects of male and female emotional behaviour, such as the dysfunctionality of emotions at work, social sharing of emotions, general emotionality etc. Examples of such items are statements like ${ }^{1}$ : Women need more support when they are sad than do men; When confronted with a crying man, I feel uncomfortable; Emotional men are not functional in industrial life; I do not like emotional men; Men show their pride about their accomplishments more than do women.

The next step was the formulation of contra-stereotypes. In accordance with the suggestions made by the authors of the original instrument, contra-stereotypical items were created by an inversion of the target individual's gender (e.g. the stereotypical belief Men should not cry was reformulated into Women should not cry). The resulting 108-item set was further supplemented with additional item content due to the concerns regarding the representativeness of the items for the emotional behaviour. Nine additional items pertaining to manifestations of surprise, disgust, and contempt were used rendering this

\footnotetext{
${ }^{1}$ A reviewer pointed out that another distinction (among the descriptive items) should be made between the items referring to both men's and women's behaviour in general as opposed to items pertaining to personal preferences for certain types of emotional behaviour in others. This is in line with the overall heterogeneity of the descriptive items.
} 
instrument a more comprehensive measure of beliefs related to emotional behaviour, in accordance with the dominant model of basic emotions (Ekman 1999a, 1999b). ${ }^{2}$

In the next step, we ran the first version of the instrument by a dozen participants (both psychologists and non-psychologists) ${ }^{3}$ to test for understandability of formulations and potential problems in their applicability after the forward-backward translation process. Based on the comments of these respondents we decided to reduce the redundant content that existed in the particular type of formulations that made direct comparisons of men and women (more-than formulations). However, the respondents that completed this version of the instrument deemed items like these as attempts by the researchers to "deceive them, lead them astray", reporting that such constant and consistent repetition "irritated them, seeing that they had already answered the same questions". Based on this, we estimated that more reliable answers could be attained through a reduction of such items. ${ }^{4}$ Items that contained direct male to female comparisons were divided, through random sampling, into two groups, with the items in the first group (50\%) keeping their stereotypical formulation, while the items in the second group were transformed into their contra-stereotypical form (50\%).

The resulting instrument had 93 items, 28 prescriptive and 65 descriptive, and this was the version we submitted to the exploratory factor analysis (EFA).

\section{METHOD}

\subsection{Sample and procedure}

The sample in this research comprised 247 respondents, members of the student population of both genders (138 female respondents, 109 male respondents), whereby around one half of them were attending the Faculty of Philosophy (62.8\%), Faculty of Electronic Engineering (10.1\%), Faculty of Sciences (6.1\%), and students of other faculties (economy, medicine, law, machine engineering, etc., 21\%) of the University of Niš. The respondents' age was between 18 and $28(\mathrm{M}=21.02, \mathrm{SD}=2.2)$. The data were provided by assigning either an electronic or a paper-pencil $(40.49 \%)$ questionnaire. The participants that filled out an electronic questionnaire were recruited via snowball sampling - the initial group of participants (students of the Faculty of Philosophy were asked to disseminate the questionnaire to their acquaintances). Informed consent that was given to every participant prior to testing consisted of information on the purpose of data collecting (attitudes towards emotional behaviour of men and women), on guaranteed anonymity of the procedure, and on the sample-based treatment of the data (participants were told that their answers would not be studied on individual basis but rather statistically).

\footnotetext{
${ }^{2}$ As manifestations of positive emotions are not socially disruptive, we assumed that norms pertaining to them are less explicitly formulated and that, therefore, measuring them using prescriptive items would not be meaningful. The authors of the original item set did the same, measuring beliefs pertaining to manifestations of pride, infatuation and enthusiasm only with descriptive items. In our research we followed the same principle.

${ }^{3}$ The data from these participants were not included in the main analysis.

${ }^{4}$ i.e. to alleviate the artificial response sets that would result from a potential frustration by the excessive redundancy in the item content
} 


\subsection{Instrument}

The instruments used in this research were derived from the Questionnaire of gender specific beliefs about emotional behaviour (Timmers et al., 2003) ${ }^{5}$ with the procedure described in detail in the section 1.1. The resulting two instruments were Beliefs about men's emotional behaviour (BEB-M) and Beliefs about women's emotional behaviour (BEB-W). ${ }^{6}$ The initial 54-item set, extracted from the original instrument, was translated into Serbian by a professional translator and this Serbian version was later translated back into English by another independent professional translator (a bilingual English-Serbian speaker) blind to the procedure and the original instrument. Finally, the author analysed any potential diversion in the meaning of the back-translated as compared to the original text and used this information to make a final form. The level of agreement with each individual item was measured using a 7-point Likert scale.

\subsection{Study rationale and data-analytic procedure}

The absence of specific assumptions regarding the structure of the instrument precludes the application of confirmatory factor analysis. The theoretical assumptions outlined in the paper (Timmers et al. 2003) do not readily translate into a measurement model - it is not clear whether these distinctions that the observed variables are based on should be modelled as different methods of measurement (method variance), different scales/factors (also, whether they are orthogonal or oblique) or sub-scales of a higher-order factor (hierarchical or a bi-factor model). Similarly, there is a lack of postulates regarding the treatment of items pertaining to the behaviour of women and those of men. Therefore, the choice of method for the testing of construct validity is exploratory in nature and guided by conceptual considerations. This is particularly important since the exploratory approach could provide us with insightful alternatives while also allowing for the structure based on the two relevant distinctions to emerge (at some level of analysis).

The first decision was to separately investigate structures of beliefs pertaining to male and female emotional behaviour. The first, substantive reason behind this decision was our focus on gender role expectations and appropriately the goal of the instrument was to investigate the complex interrelations of such beliefs within the framework of individual gender roles. This had the added benefit of avoiding cross-relations which would additionally burden the analysis, and which could obfuscate potentially important relations between beliefs in the context of a single gender role. The second, statistical reason behind this decision lies in the problem of extracted factor replicability (their number and factor-item structure) or, in other words, the ratio of items to respondents which strongly favours configurations in which sets of items targeting the emotional behaviour of men are separate from those targeting the emotional behaviour of women. Therefore, this paper aims to investigate the structures of two potential instruments: Beliefs about men's emotional behaviour (BEB-M) and Beliefs about women's emotional behaviour (BEB-W).

The presence of multiple grouping principles (subtle vs. blatant formulations, powerful emotions vs. powerless emotions, different aspects of emotional behaviour) suggest a potentially complex hierarchical structure of the questionnaire, as well as a complex

\footnotetext{
${ }^{5}$ Internal consistency measures $(\alpha)$ for items sets (of the original instrument) developed in studies 1 and 2 of Timmers et al. (2003) ranged from .88 to .91 for overall domains (stereotypical, contra-stereotypical; descriptive, prescriptive) regardless of the target gender.

${ }^{6}$ The rationale for this splitting is provided in the next section.
} 
relationship between factors on different (and adjacent) levels of hierarchy. In the same vein, analysis of the interrelations themselves might provide potential insights into the dynamics of the process through which specific clusters of beliefs are extracted from general beliefs (on a potential continuum from general principles/norms of behaviour to specific clusters that describe normative expectations within certain contexts), as well as their differential importance for gender role suited adaptation.

"Bass-ackwards" is a top-down sequential-factors analysis put forth by Goldberg (2006) as a procedure that allows the studying of hierarchical ${ }^{7}$ representations of complex factor structures. The first step of this procedure is the extraction of the first unrotated principal component (FUPC) on the first hierarchical level (first step) that describes whatever is the most common in the data. On the second level of hierarchy (in the second step), two rotated components are extracted, and this process continues until not a single item has its highest loading on the additional factor (Goldberg does not specify the type of rotation - rather he encourages researchers to try out both orthogonal and oblique). However, we have decided that, for the purposes of this research, the interpretability of isolated factors would be used as a criterion for the suspension of hierarchy building. ${ }^{8}$ Still, this criterion is supplemented by other (statistically more sound) criteria, during the selection of an adequate number of factors, which would serve as reliable measures of the instrument's constructs (discussed later in the text). Finally, factor scores of each individual factor on each separate level were calculated, saved and used, as per Goldberg's suggestion, as "path coefficients" (Goldberg $2006,357)^{9}$ between factors on adjacent levels of the data tree. The factor extraction method we used was principal component analysis with oblique (promax) rotation.

Later developments of the "bass-ackwards" analysis showed that sequential factor analysis could produce a factor structure matching either a (pure) hierarchical or list scheme (arrangement) or a combination of the two (Loehlin \& Goldberg 2014a, 2014b). Therefore, within the scope of this paper, the term "hierarchical" will be used in a descriptive sense with the representations of factor solutions themselves being sequential in nature and serving as a "flow-chart of factor emergence" (Goldberg 2006, 356).

Still, when it comes to the measuring structure of a stereotype, two criteria were used to ascertain which level of hierarchy would serve as a reliable structure of measurement for the instrument: the usefulness of the variables/factors (their interpretability, serving as a substantial criterion) and statistical techniques for the selection of an adequate (replicable) number of factors, such as parallel analysis (Horn 1965) and minimum average partial correlation (MAP: Velicer 1976), as implemented in SPSS syntax (O’Connor 2000).

\footnotetext{
${ }^{7}$ Some authors (Forbs, Kotov, Ruggero, Watson, Zimmerman, \& Krueger 2017) use the term "tier" of hierarchy in order to make distinction between levels of hierarchy and nested structural components. Others refer to the procedure as "Goldberg's trait-tier mapping procedure" (Chapman, Weiss, Barret, \& Duberstein 2013) as means to study "a hierarchy of increasing scale differentiation" (Chapman et al. 2013, 480).

${ }^{8}$ As suggested by Gorsuch (2003) the decision on the number of factors/components to retain is still semisubjective despite the advanced procedures such as PA and MAP. Thus, Gorsuch maintains that authors should take interpretability into account when making the final decision on the dimensionality of factor space but with insistence on retaining greater rather than lesser number of dimensions. This is in line with simulation studies that show that underextraction can lead to more error variance in factors and factor loadings (Wood, Tataryn, \& Gorsuch 1996). Finally, this provides us with further rationale for the use of the sequential factoring (Goldberger 2006) since this method provides a framework for studying the way the factors differentiate as the number of dimensions becomes greater thus making room for choosing the optimal solution as well as inferences about the nature of the dimensions (as it relates to their origins, higher-order factors that they are derived from).

${ }^{9}$ Strictly speaking, these are zero-order correlations that serve as path estimates and are only descriptively referred to as "path coefficients" along the terminology promoted by the author of the procedure.
} 


\section{RESULTS}

\subsection{Preliminary factor analyses and item exclusion criteria}

The first step in preliminary factor analysis and item exclusion was as follows. We ran EFAs sequentially aimed at testing the structure as previously described. However, in this process we found that a number of items had multiple loading issues which obscured the otherwise evident and readily interpretable structure. This prompted us to explore the reasons behind this problematic item-loading pattern in order to guide item exclusion/selection.

Item exclusion criteria used in the instrument are the following: 1) complex formulations, whose content does not clearly reveal what a respondent is agreeing with (content analysis; e.g. I do not like women who show their pride because that is boasting behaviour), 2) items that have low factor loadings (across factors), 3) items that have non-discriminant factor loading on multiple factors, and 4) item loadings that are not interpretable in the context of otherwise interpretable factors (which prompted examinations of the reasons for such a loading pattern).

However, in construction of the BEB-M the exclusion process had two steps. In the second step, we examined the final four-factor solution (see next section) in BEB-M and found that the three additional items need to be excluded due to interpretability reasons (discussed later in this section).

Tables 1 and 2 showcase the items that met the exclusion criteria.

Table 1 lists the items excluded from the instrument that measures beliefs about the emotional behaviour of men (BEB-M). The first six items are formulated in a complex way, e.g. they consist of two parts, and it remains unknown whether the respondents evaluated the degree of agreement with the first part of the item, which refers to behaviour, or with the second part, which refers to the cause of such behaviour. Each of these items, apart from the content, meets at least one more exclusion criterion - either one that refers to the pattern of factor loadings of that item. The item Men bother other people with their feelings is categorised as a stereotypical descriptive item because it is expected to measure the negative attitude towards the sensitivity of men (men's feelings are a burden); however, it can be viewed as contra-stereotypical, so the person that agrees with it could consider that men are so intensely sensitive that they burden the people around them (the intensity of sensitivity is a burden). Content like this probably makes for its non-discriminant loading on multiple factors. The item Men are more able to hide their fear than do women differs from the other items in the instrument by the fact that it refers to the belief that men are able to control their fear, and not to the norm linked to its expression. It is possible that the success of emotional regulation is a component of gender stereotypes about emotional behaviour, and that it would stand out as an additional variable/factor if there were enough items in the instrument that would be focused on measuring it. In other words, it is possible that this content is underrepresented in the initial item pool. The item Men are less complicated in their feelings than women is insufficiently specific in its content, which could probably explain the fact that it does not load on extracted factors, as well as its non-discrimination. 
Table 1 The list of items excluded from the instrument BEB-M with exclusion/removal criteria

\begin{tabular}{|c|c|c|c|c|c|}
\hline & Item & Content & $\begin{array}{l}\text { Low factor } \\
\text { loading }\end{array}$ & $\begin{array}{c}\text { Non- } \\
\text { discrimination }\end{array}$ & $\begin{array}{c}\text { Non- } \\
\text { interpretability }\end{array}$ \\
\hline \multirow[t]{10}{*}{ 1. step } & $\begin{array}{l}\text { It is functional to have a man in the } \\
\text { board of directors, because they are } \\
\text { sensitive for the needs of employees. CD }\end{array}$ & $\mathrm{x}$ & $\mathrm{X}$ & & \\
\hline & $\begin{array}{l}\text { Because men are sensitive, they are } \\
\text { capable of raising children. CD }\end{array}$ & $\mathrm{x}$ & & & $\mathrm{X}$ \\
\hline & $\begin{array}{l}\text { Men do not dare to show their anger } \\
\text { because they take into account other } \\
\text { people's feelings. CD }\end{array}$ & $\mathrm{x}$ & $\mathrm{X}$ & $\mathrm{x}$ & $\mathrm{x}$ \\
\hline & Men hide their fear by acting tough. SD & $\mathrm{X}$ & & $\mathrm{X}$ & $\mathrm{X}$ \\
\hline & $\begin{array}{l}\text { I do not like men who show their pride, } \\
\text { because it is boasting behaviour. SD }\end{array}$ & $\mathrm{X}$ & & & $\mathrm{x}$ \\
\hline & $\begin{array}{l}\text { Martial arts are more suitable for men } \\
\text { than for women, because they can } \\
\text { express their aggression. SD }\end{array}$ & $\mathrm{x}$ & & & $\mathrm{x}$ \\
\hline & $\begin{array}{l}\text { When men are together, all they talk } \\
\text { about is their feelings. CD }\end{array}$ & & & $\mathrm{x}$ & $\mathrm{x}$ \\
\hline & $\begin{array}{l}\text { Men bother other people with their } \\
\text { feelings. SD }\end{array}$ & $\mathrm{X}$ & & $\mathrm{x}$ & \\
\hline & $\begin{array}{l}\text { Men are more able to hide their fear } \\
\text { than do women. SD }\end{array}$ & $\mathrm{X}$ & & & $\mathrm{x}$ \\
\hline & $\begin{array}{l}\text { Men are less complicated in their } \\
\text { feelings than women. SD }\end{array}$ & $\mathrm{X}$ & $\mathrm{x}$ & $\mathrm{x}$ & \\
\hline \multirow[t]{3}{*}{ 2. step } & $\begin{array}{l}\text { Emotional men are not functional in } \\
\text { industrial life. SD }\end{array}$ & & & & $\mathrm{x}$ \\
\hline & $\begin{array}{l}\text { I do not like to discuss my feelings } \\
\text { with a man. SD }\end{array}$ & & & & $\mathrm{x}$ \\
\hline & $\begin{array}{l}\text { I do not like men who want to discuss } \\
\text { their feelings. SD }\end{array}$ & & & & $\mathrm{x}$ \\
\hline
\end{tabular}

Note. SD - stereotypical descriptive items; CD - contra-stereotypical descriptive items.

The final three items were excluded in the second step in order to improve the interpretability (conceptual clarity) of the factor Ban on displaying powerless emotions (see table 3) which in turn consisted exclusively of prescriptive stereotypes. One of the potential reasons that offers a clue to this is the pattern of distributions (arithmetic means and skewness) of the mentioned items - these are all difficult items that probably covariate with the items that gather on the aforementioned factor (due to their shared difficulty). We decided to pursuit the conceptual distinctiveness only in the case of the subtle-blatant (descriptive-prescriptive) distinction because the distinction between contra- and stereotypes is more likely to be culturally variant since it is based on the social learning of the gender roles. 
Table 2 The list of items excluded from the instrument BEB-W with exclusion/removal criteria

\begin{tabular}{|c|c|c|c|c|}
\hline Item & Content & $\begin{array}{l}\text { Low factor } \\
\text { loading }\end{array}$ & $\begin{array}{c}\text { Non- } \\
\text { discrimination }\end{array}$ & $\begin{array}{c}\text { Non- } \\
\text { interpretability }\end{array}$ \\
\hline $\begin{array}{l}\text { It is functional to have a woman in the board } \\
\text { of directors, because they are sensitive for the } \\
\text { needs of employees. SD }\end{array}$ & $\mathrm{x}$ & $\mathrm{X}$ & & \\
\hline $\begin{array}{l}\text { Because women are sensitive, they are } \\
\text { capable of raising children. SD }\end{array}$ & $\mathrm{x}$ & & & $\mathrm{x}$ \\
\hline $\begin{array}{l}\text { Women do not dare to show their anger } \\
\text { because they take into account other people's } \\
\text { feelings. SD }\end{array}$ & $\mathrm{x}$ & & & $\mathrm{x}$ \\
\hline Women hide their fear by acting tough. CD & $\mathrm{x}$ & & & $\mathrm{x}$ \\
\hline $\begin{array}{l}\text { I do not like women who show their pride, } \\
\text { because it is boasting behaviour. CD }\end{array}$ & $\mathrm{x}$ & & & $\mathrm{x}$ \\
\hline $\begin{array}{l}\text { Women like action movies more than women, } \\
\text { because they are more able to identify with } \\
\text { that kind of movies. CD }\end{array}$ & $\mathrm{x}$ & & & $\mathrm{x}$ \\
\hline
\end{tabular}

Note. SD - stereotypical descriptive items; CD - contra-stereotypical descriptive items.

Table 2 lists the items excluded from the instrument that measures beliefs about the emotional behaviour of women (BEB-W). The items singled out as formulated in a complex way in BEB-M (see previous paragraph) have also indicated a similar problem in the case of women. According to these criteria, all the items from the initial set have been excluded. Apart from this reason, each one of the listed items also fulfils a statistical reason for exclusion.

The assembled instrument draft, which will have its potential hierarchical structure (sequential item-factor structures) examined in this paper, consists of 35 items that measure beliefs about men's emotional behaviour (BEB-M) and 39 items that measure beliefs about women's emotional behaviour (BEB-W).

\subsection{Latent structure of the instrument Beliefs about men's emotional behaviour (BEB-M)}

Principal component analysis (PCA) was applied to BEB-M items. The results of KMO measure of sampling adequacy (.868) and Bartlett's test of sphericity $(\chi 2(595)=3206.81, \mathrm{p}<$ $.001)$ were satisfactory. The first ten eigenvalues (greater than one) are as follows: 8.96, 2.87, $1.90,1.76,1.34,1.28,1.22,1.19,1.08,1.04$.

The structure of BEB-M can be described with a four-dimension solution as suggested by parallel analysis (PA), while MAP lends support for a 3 to 5 dimensions solution (with average partial correlations being .0112,.0112, .0113 for 3, 4, and 5 dimensions respectively). However, both of these methods are shown to be erroneous particularly in the case of highly correlated factors (oblique solutions; Caron, 2018), where PA is prone to underestimation while MAP is prone to overestimation of the dimensionality of data. Hence, we decided to adhere to interpretability of solutions when choosing the best way to describe the dimensionality of data (Gorsuch, 2003). 
Table 3 Overview of the factor-items structure (pattern matrix) through various factor solutions (BEB-M)

\begin{tabular}{|c|c|c|c|c|c|c|c|}
\hline \multirow{2}{*}{\multicolumn{2}{|c|}{ Items }} & \multicolumn{2}{|c|}{$\begin{array}{c}\text { Second level: } \\
\text { three-factor } \\
\text { solution }(39.16 \%)^{\mathrm{a}} \\
\end{array}$} & \multicolumn{4}{|c|}{$\begin{array}{l}\text { Third level: } \\
\text { four-factor solution } \\
(44.19 \%)^{\mathrm{a}}\end{array}$} \\
\hline & & 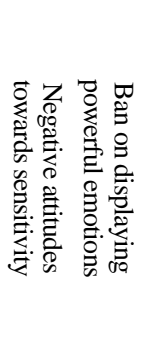 & 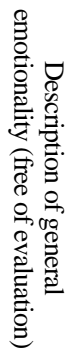 & 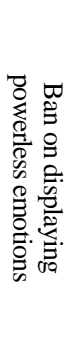 & 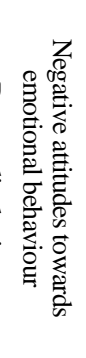 & 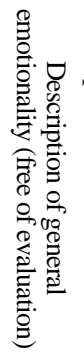 & 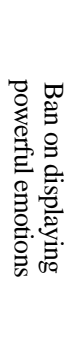 \\
\hline$\overline{\mathrm{CP}}$ & Men should not show their disgust. & $.007 \quad .689$ & .029 & .660 & -.115 & -.007 & .308 \\
\hline $\mathrm{CP}$ & Men should not show their contempt. & $-.152 \overline{\mathbf{8 1 2}}$ & .177 & .595 & $5-.135$ & .061 & $\overline{.514}$ \\
\hline $\mathrm{CP}$ & Men should not be aggressive. & $-.410 \underline{\overline{\mathbf{3 9 7}}}$ & .345 & -.099 & -.042 & .116 & $\overline{\mathbf{5 9 4}}$ \\
\hline $\mathrm{CP}$ & Men should not show their anger. & $-.080 \overline{\mathbf{7 9 1}}$ & .178 & .633 & $3-.113$ & .087 & .455 \\
\hline & $\begin{array}{l}\text { Occupations where it is necessary to keep a cool head, like } \\
\text { police-officers, surgeons or jet-fighter pilots are less suitable for } \\
\text { men because they are not able to do so. }\end{array}$ & $-.043 \quad .212$ & .246 & .292 & $2-.253$ &. $\mathbf{3 9 6}$ & -.151 \\
\hline $\mathrm{CD}$ & Men get jealous more easily than women. & $.108 \quad .176$ & .439 & .161 & .028 & .471 & .013 \\
\hline $\mathrm{CD}$ & It is easier to talk with men about your feelings than with women. & $.286-.301$ & .265 & -.112 & .135 & .384 & -.338 \\
\hline $\mathrm{CD}$ & Men are more fearful by nature than women. & $-.156 \quad .047$ & .660 & -.229 & .012 &.$\underline{.608}$ & .151 \\
\hline $\mathrm{CD}$ & Men are more emotionally unstable than women. & $.011 \quad .144$ & .627 & -.106 & .174 & $\overline{.516}$ & .256 \\
\hline $\mathrm{CD}$ & Men stay angry longer than women. & $.272-.122$ & $\overline{\mathbf{3 4 1}}$ & .111 & .006 & $\overline{.524}$ & -.371 \\
\hline $\mathrm{CD}$ & Men are offended more easily than women. & $-.019 \quad .052$ &. $\mathbf{5 7 3}$ & -.055 & $5-.013$ & .604 & -.007 \\
\hline $\mathrm{CD}$ & $\begin{array}{l}\text { Men respond more enthusiastically than do women when you talk } \\
\text { about something you like yourself. }\end{array}$ & $.250 \quad .110$ &.$\overline{491}$ & .107 & 7.196 & $\underline{.483}$ & .034 \\
\hline $\mathrm{CD}$ & Men are warmer than women. & $.104-.158$ & .362 & -.072 & $2-.015$ & .483 & -.256 \\
\hline SD & Men show disgust more often than do women. & .024 .154 & .465 & .151 & $1-.094$ & $\overline{.554}$ & -.075 \\
\hline $\mathrm{SD}$ & $\begin{array}{l}\text { Men show their pride about their accomplishments more than do } \\
\text { women. }\end{array}$ & $.083-.005$ & .492 & -.210 & .268 & $\underline{.365}$ & .212 \\
\hline SD & It is not professional when a man cries at work. & $.632-.101$ & 0.033 & .066 & .600 & -.083 & .054 \\
\hline SD & Men who show their emotions at work are hard to take seriously. & $\overline{.786}-.266$ & .077 & .022 & .669 & .022 & -.125 \\
\hline SD & I do not like emotional men. &. $\mathbf{6 8 4} \quad 099$ & -.084 & .409 & .461 & -.112 & -.028 \\
\hline SD & I do not like jealous men. & $-\overline{067} \quad .168$ & .007 & -.172 & $\overline{\mathbf{3 1 0}}$ & -.298 & .567 \\
\hline SD & Men who show too much that they are in love are too sentimental. &. $\mathbf{4 3 0} \quad .072$ & .200 & .052 & $\overline{\mathbf{5 1 0}}$ & .029 & .246 \\
\hline SD & $\begin{array}{l}\text { I do not like men who respond with excessive enthusiasm, } \\
\text { because it is too much. }\end{array}$ & $\underline{\overline{\mathbf{3 9 0}}} .038$ & .135 & .078 &.$\overline{404}$ & .027 & .135 \\
\hline SD & $\begin{array}{l}\text { It is better that men who have a management position do not } \\
\text { show their feelings. }\end{array}$ & $. .668-.080$ & .251 & .002 & .704 & .086 & .147 \\
\hline SD & $\begin{array}{l}\text { When men become emotional easily, they are not suitable for } \\
\text { management positions. }\end{array}$ & $.782-.226$ & .014 & .077 & .647 & -.039 & -.117 \\
\hline SD & $\begin{array}{l}\text { I do not like men who cry easily, because I think it is } \\
\text { manipulative behaviour. }\end{array}$ & $\underline{.668}-.213$ & .213 & -.085 & $\underline{.683}$ & .086 & .034 \\
\hline SD & When confronted with a crying man, I feel uncomfortable. & .010 & .209 & .121 & .442 & .138 & .051 \\
\hline SP & Men should not show their sadness. & $\mathbf{. 5 1 0} \quad .277$ & -.133 & .658 & $\overline{.121}$ & -.026 & -.158 \\
\hline SP & Men should not show their disappointment. &.$\overline{\mathbf{3 0 2}} \quad .536$ & .023 & .693 & .055 & .036 & .127 \\
\hline SP & Men should not show their fear. & $\begin{array}{cc}. \mathbf{4 4 7} & .397 \\
\end{array}$ & .023 & .665 & .127 & .081 & -.020 \\
\hline SP & Men should not show their surprise. & 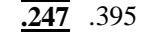 & -.054 &.$\overline{631}$ & -.067 & .046 & -.060 \\
\hline SP & Men should not cry. &.$\overline{\mathbf{4 5 9}} \quad .373$ & -.194 &.$\overline{730}$ & .077 & -.102 & -.094 \\
\hline SP & Men should control their feelings. & $\overline{.652}-.037$ & -.035 &.$\overline{239}$ &.$\underline{485}$ & -.069 & -.061 \\
\hline SP & Men who express their fear are weak. & $\overline{.661} .155$ & -.082 & .568 & $\underline{.289}$ & .000 & -.184 \\
\hline SP & Men who express their disappointment are weak. &. $\mathbf{3 7 5} .548$ & -.100 & .869 & -.040 & .013 & -.047 \\
\hline $\mathrm{SP}$ & Men who express their emotions are weak. &. $\mathbf{5 1 0} \quad .346$ & -.138 & .712 & 2.126 & -.048 & -.106 \\
\hline SP & Men who express their sadness are weak. & $\overline{\mathbf{5 3 7}} \quad .382$ & -.085 & $\overline{.713}$ & ב. 185 & -.030 & -.038 \\
\hline
\end{tabular}


Table 3 presents an overview of the factor-items structure across two final factor solutions. As can be seen from the four-factor solution, the items referring to the men's emotional behaviour usually spread out according to a schema that divides the items of the instrument according to the distinctions contra-stereotypical - stereotypical and prescriptive - descriptive.

Thus, the factor that includes the common variance of the set of items that refer to the negative attitudes towards emotional behaviour, in accordance with its name, mostly consists of items that the authors of the initial version of the instrument have included in the category of stereotypical descriptive beliefs. It also includes the items that refer to the negative attitudes towards emotional behaviour at work.

In accordance with the suggested structure, the factor Ban on displaying powerless emotions gathers prescriptive stereotypical beliefs, while the factor Ban on displaying powerful emotions is mostly comprised of the items that measure prescriptive contrastereotypical beliefs. However, there are some exceptions.

The items that comprise the factor Ban on displaying powerful emotions (prescriptive contra-stereotypical beliefs) have also been loaded on the factor Ban on displaying powerless emotions (prescriptive stereotypical beliefs). Pure loadings on former factor are only shown by the item Men should not be aggressive. This finding may suggest the bi-factor nature of the scale - one part of the shared variance stems from the prescriptive nature of the items (imperative statement) - common to both factors, while the second part stems from the differential content of the factors (different nature of the emotions and their required

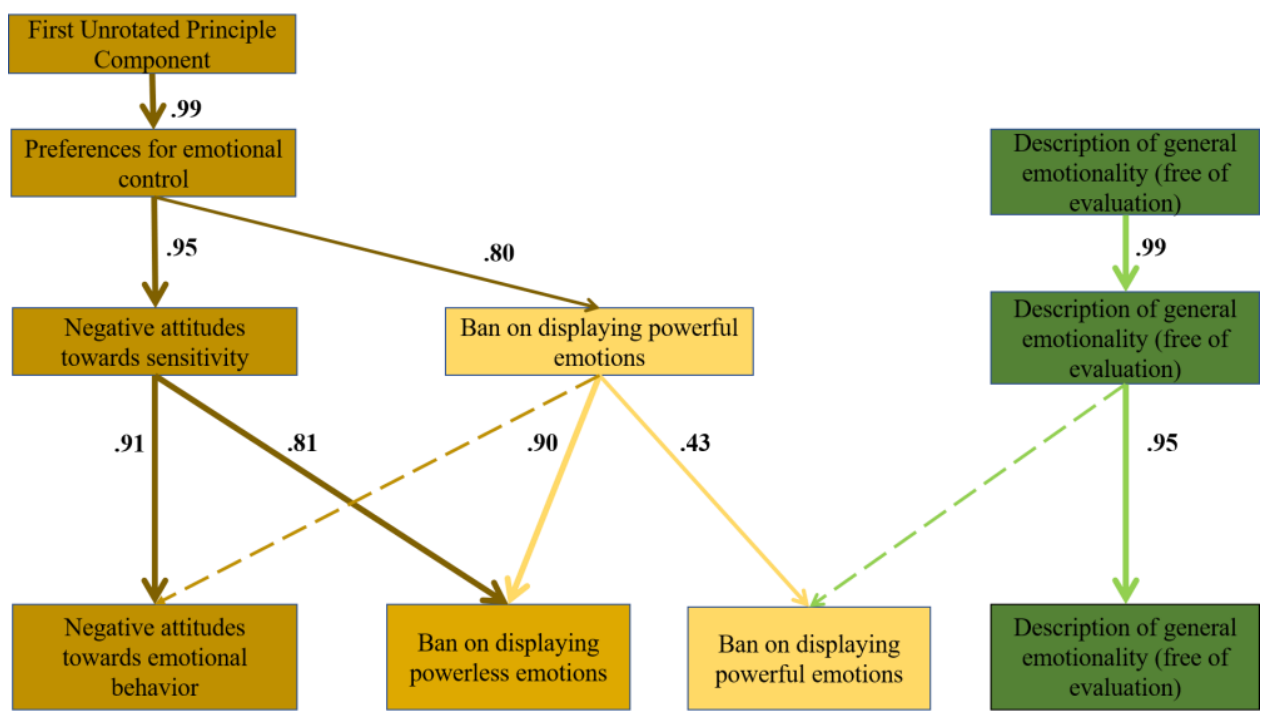

Fig. 1 Review of the factor structures BEB-M across different number of components. Only correlations beyond .3 were plotted. The thickness of the path corresponds to the magnitude of the association (with dashed lines representing a range .3-.4) 
manifestation control). Nevertheless, by inspecting the arithmetic means of the items, this type of a pattern becomes somewhat more clear - the loadings of the first factor (Ban on displaying powerless emotions) are probably a consequence of the items' difficulty (small arithmetic means and high positive skewness, implying low endorsement rates), which could be a possible explanation for the fact that the first factor does not load the item about the prohibition of aggressiveness, because it is an easy item (high endorsement rates - negative skew and high mean). Finally, this explanation may suggest that the first factor alone (prescriptive stereotypes) is the difficulty factor, e.g. it can point to its potentially statistically artefactual nature.

\subsection{Latent structure of the instrument Beliefs about women's emotional behaviour (BEB-W)}

PCA was applied to items pertaining to beliefs about the emotional behaviour of women (BEB-W). The results of the KMO measure of sampling adequacy (.871) and Bartlett's test of sphericity $(\chi 2(780)=3652.88, \mathrm{p}<.001)$ were satisfactory. The first nine eigenvalues (those greater than one) are as follows: 9.5, 3.32, 2.62 1.67,1.55 1.41, 1.19, 1.12 , and 1.12 .

Despite the interpretable five-dimension belief structure pertaining to the emotional behaviour of women (BEB-W), the parallel analysis results (Horn, 1965) suggest that four dimensions are needed for an optimal description of BEB-W, while results obtained via MAP lends support for 3 to 5 dimensions solution (with average partial correlations being .0106, .0108, .0107 for 3,4 , and 5 dimensions respectively).

When it comes to the five-factor solution of the belief about the women's emotional behaviour, given in Table 4, the layout of the factor loadings of the items completely suits the theoretically foreseen distinctions, thus creating homogenous and clearly thematised clusters of beliefs. The homogenous cluster of items that thematise proper emotional behaviour in the work-related context, which separates itself from the factors that prescribe emotional behaviour in other contexts, can clearly be distinguished on the four-factor level. This is not the case with the corresponding set of items that thematise men's work-related behaviour.

It is important to note that an item that refers to the prohibition of the jealousy manifestation, which additionally loads on the factor Ban on displaying powerful emotions in BEB-M (besides expected loading on Negative attitudes towards emotional behavior; see Table 3). This finding has not been replicated in the item set of beliefs about women's emotional behaviour, which may indicate a different meaning of jealousy manifestation as a social signal in men. 
Table 4 Overview of the structure factor-items through various factor solutions (BEB-W)

\begin{tabular}{|c|c|c|c|c|c|c|c|c|c|c|}
\hline \multirow{2}{*}{\multicolumn{2}{|c|}{ Items }} & \multicolumn{4}{|c|}{$\begin{array}{c}\text { Third level: } \\
\text { four-factor solution } \\
(41.27 \%)^{\mathrm{a}}\end{array}$} & \multicolumn{5}{|c|}{$\begin{array}{c}\text { Fourth level: } \\
\text { five-factor solution } \\
(45.17 \%)^{\mathrm{a}}\end{array}$} \\
\hline & & 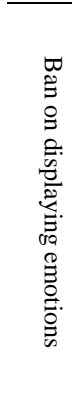 & 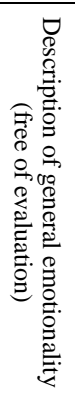 & 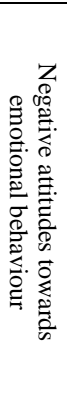 & 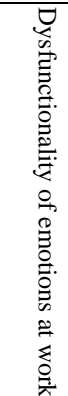 & 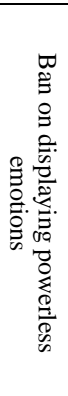 & 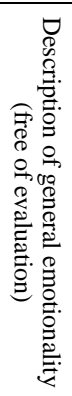 & 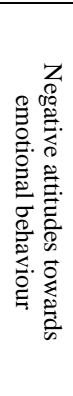 & 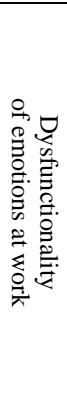 & 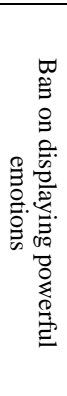 \\
\hline $\mathrm{CP}$ & Women who express their sadness are weak. & .348 & -.108 & .403 & .096 & .555 & -.053 & .246 & .042 & -.051 \\
\hline $\mathrm{CP}$ & Women should not show their sadness. & .666 & -.071 & .094 & .106 & .713 & .001 & -.045 & .031 & .120 \\
\hline $\mathrm{CP}$ & Women should not show their disappointment. & .696 & -.066 & -.023 & .117 & .555 & -.092 & -.046 & .105 & .312 \\
\hline $\mathrm{CP}$ & Women should not show their fear. & $\overline{.634}$ & -.021 & .068 & .012 & $\overline{\mathbf{5 1 8}}$ & -.032 & .021 & .002 & .269 \\
\hline $\mathrm{CP}$ & Women should not cry. & $\overline{\mathbf{5 9 2}}$ & -.137 & .100 & .190 & $\overline{\mathbf{7 5 0}}$ & -.028 & -.075 & .084 & .003 \\
\hline $\mathrm{CP}$ & Women who express their fear are weak. & $\overline{.490}$ & -.157 & .197 & .252 & $\overline{.754}$ & -.030 & -.008 & .131 & -.101 \\
\hline $\mathrm{CP}$ & Women should not show their surprise. & $\overline{.597}$ & .088 & .113 & -.088 &.$\overline{473}$ & .091 & .051 & -.099 & .255 \\
\hline $\mathrm{CP}$ & Women who express their disappointment are weak. & .626 & -.062 & .191 & .106 & .751 & .034 & .014 & .015 & .046 \\
\hline $\mathrm{CP}$ & Women who express their emotions are weak. & .525 & -.149 & .334 & .151 & .826 & -.004 & .086 & .027 & -.125 \\
\hline$\overline{\mathrm{CP}}$ & Women should control their feelings. & .044 & .086 & .287 & .254 & .058 & -.013 & .325 & .292 & .095 \\
\hline $\mathrm{CD}$ & Women bother other people with their feelings & .097 & .146 & .510 & -.150 & .165 & .129 & .433 & -.130 & .017 \\
\hline $\mathrm{CD}$ & I do not like emotional women. & .060 & -.108 &.$\overline{608}$ & .094 & .432 & -.033 & $\overline{\mathbf{4 1 4}}$ & .033 & -.246 \\
\hline $\mathrm{CD}$ & I do not like women who want to discuss their feelings. & .097 & -.133 &.$\overline{622}$ & -.008 & .339 & -.127 & .495 & -.012 & -.105 \\
\hline CD & When confronted with a crying woman, I feel uncomfortable. & -.092 & .109 &.$\overline{638}$ & -.059 & -.103 & -.046 &.$\overline{686}$ & .051 & .117 \\
\hline $\mathrm{CD}$ & $\begin{array}{l}\text { Women who show too much that they are in love are too } \\
\text { sentimental. }\end{array}$ & -.051 & .353 & $\underline{. \overline{445}}$ & .042 & .089 & .370 &.$\overline{356}$ & .020 & -.089 \\
\hline $\mathrm{CD}$ & $\begin{array}{l}\text { I do not like women who cry easily, because I think it is } \\
\text { manipulative behaviour. }\end{array}$ & -.029 & .188 & .632 & -.051 & .030 & .101 & .610 & .009 & .045 \\
\hline $\mathrm{CD}$ & $\begin{array}{l}\text { I do not like women who respond with excessive enthusiasm, } \\
\text { because it is too much. }\end{array}$ & .073 & .111 & $\underline{.363}$ & .060 & .085 & .040 & .362 & .097 & .083 \\
\hline $\mathrm{CD}$ & I do not like jealous women. & -.262 & .032 & .531 & -.222 & -.391 & -.178 & .668 & -.052 & .171 \\
\hline $\mathrm{CD}$ & I do not like to discuss my feelings with a woman. & .008 & .001 & $\overline{\mathbf{7 0 0}}$ & -.168 & .245 & .023 &.$\overline{554}$ & -.168 & -.140 \\
\hline$\overline{\mathrm{CD}}$ & $\begin{array}{l}\text { Women who show their emotions at work are hard to take } \\
\text { seriously. }\end{array}$ & .001 & .026 & -.139 & .751 & .065 & -.050 & -.056 & .727 & .030 \\
\hline $\mathrm{CD}$ & Emotional women are not functional in industrial life. & .231 & .040 & .014 & .451 & 227 & -.022 & .047 & .441 & .128 \\
\hline $\mathrm{CD}$ & $\begin{array}{l}\text { It is better that women who have a management position do } \\
\text { not show their feelings. }\end{array}$ & -.009 & .146 & -.028 & .717 & .143 & .126 & -.016 & $\overline{.656}$ & -.061 \\
\hline $\mathrm{CD}$ & It is not professional when a woman cl & -.029 & .091 & -.243 & .879 & 056 & .034 & -.160 & .829 & -.005 \\
\hline $\mathrm{CD}$ & $\begin{array}{l}\text { When women become emotional easily, they are not suitable } \\
\text { for management positions. }\end{array}$ & -.008 & .096 & .122 & .547 & .036 & -.008 & .192 & $\overline{.561}$ & .066 \\
\hline $\mathrm{CD}$ & $\begin{array}{l}\text { Women are more direct in expressing their anger than are } \\
\text { men. }\end{array}$ & .315 & .383 & -.038 & -.279 & .104 & .406 & -.063 & -.282 & .208 \\
\hline $\mathrm{CD}$ & Women show contempt more often than do men. & -.002 & .625 & .185 & .009 & -.157 & .557 & .230 & .041 & .167 \\
\hline SD & Women talk more often about their emotions than men. & -.212 & .557 & .128 & .016 & -.136 & .622 & .064 & -.036 & -.140 \\
\hline SD & Women fall more easily in love than men. & .208 & .512 & .046 & -.161 & .173 & .611 & -.064 & -.229 & .021 \\
\hline SD & Women need more support when they are sad than do men. & .311 &.$\overline{496}$ & -.128 & .050 & .233 &.$\overline{578}$ & -.202 & -.029 & 089 \\
\hline SD & Women are more sensitive than men. & .006 & .673 & -.087 & .214 & -.034 & $\overline{.718}$ & -.111 & .148 & .012 \\
\hline SD & Women get angry more easily than men. & .240 & $\overline{.656}$ & .032 & -.060 & .066 &.$\overline{668}$ & .010 & -.082 & .185 \\
\hline SD & Women are more curious about their feelings than men. & -.243 &.$\overline{633}$ & .135 & .159 & -.213 & $\overline{.640}$ & .128 & .131 & -.071 \\
\hline SD & Women show surprise more often than do men. & -.032 & .634 & -.050 & .151 & -.043 & .692 & -.089 & .084 & -.028 \\
\hline SD & When women are together, all they talk about is their feelings. & .087 &.$\overline{357}$ & .302 & -.042 & .055 &.$\overline{329}$ & .275 & -.029 & .084 \\
\hline SD & $\begin{array}{l}\text { Because women are more sensitive than men, they are more } \\
\text { suitable for nursing jobs. }\end{array}$ & -.180 & $\underline{.555}$ & .088 & .329 & -.015 &.$\overline{630}$ & .012 & .239 & -.186 \\
\hline SP & Women should not show their disgust. & .776 & .164 & -.184 & -.145 & .163 & -.047 & .010 & -.012 & .757 \\
\hline SP & Women should not show their contempt. & $\overline{.726}$ & .269 & -.138 & -.242 & .043 & .028 & .085 & -.080 & $\overline{.809}$ \\
\hline SP & Women should not be aggressive. & .308 & .334 & -.238 & .131 & -.265 & .063 & .055 & .286 &.$\overline{646}$ \\
\hline SP & Women should not show their anger. & .828 & .045 & -.155 & -.069 & .370 & -.091 & -.048 & .008 &.$\overline{622}$ \\
\hline
\end{tabular}

Note. Pattern matrix. SP - stereotypical prescriptive items; SD - stereotypical descriptive items; CP - contrastereotypical prescriptive items; $\mathrm{CD}$ - contra-stereotypical descriptive items. ${ }^{\text {a }} \%$ of variance explained. 


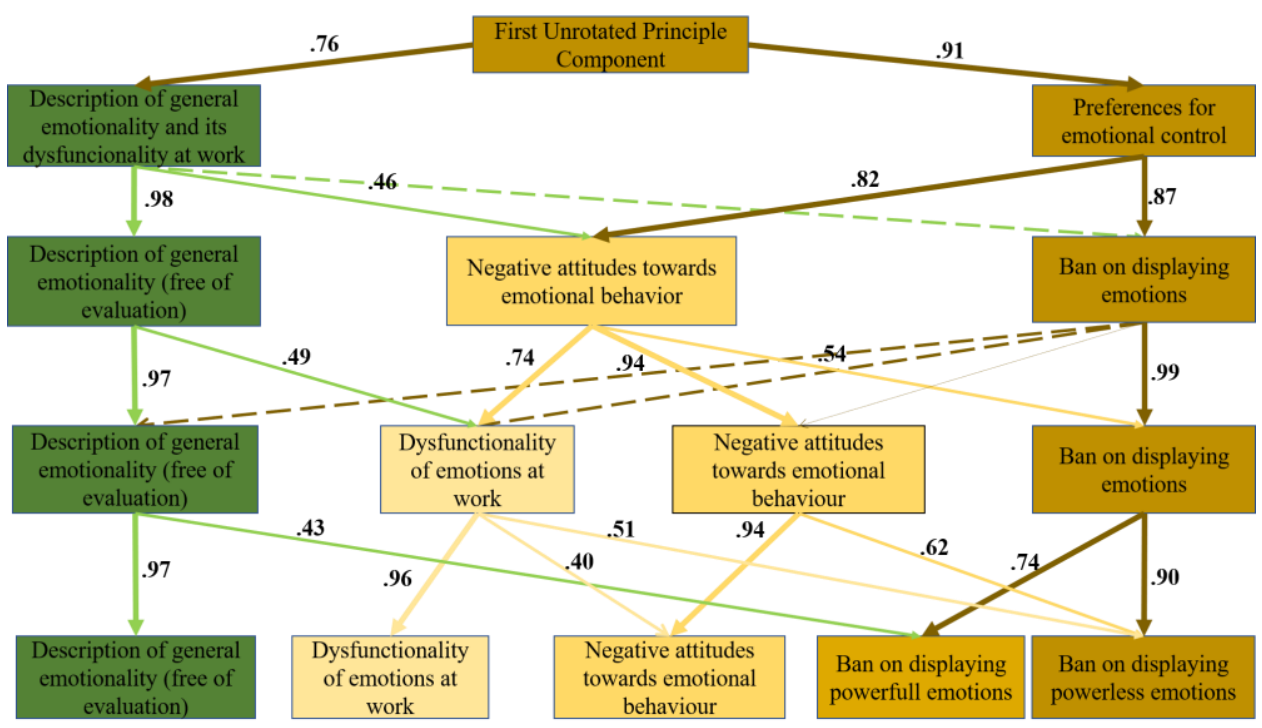

Fig. 2 Review of the factor structures BEB-W across different number of components. Only correlations beyond .3 were plotted. The thickness of the path corresponds to the magnitude of the association (with dashed lines representing a range .3-.4)

As can be seen from Fig. 2, Preferences for emotional control, in the structure BEB-W, is not independent from Description of general emotionality, on the second level of hierarchy, which can be explained by introducing the cluster of belief about the dysfunctionality of emotions at work into the content of the second factor. The factor Dysfunctionality of emotions at work stays related to the Description of general emotionality (free of evaluation) across levels of hierarchy.

By inspection Fig. 1, the independency of the factor that possesses an evaluativeprescriptive content (Preferences for emotional control) and the factor that possesses predominantly descriptive content (Description of general emotionality (free of evaluation), on the second level of hierarchy, can be distinguished in the case of men, while this relation between the two does not occur in the belief structure about the women's emotional behaviour, in which case there is a greater interdependence of the two types of beliefs - both are highly correlated with the FUPC (Fig. 2). Description of general emotionality (free of evaluation) factor retains its consistency and separation across levels in men as opposed to the structure of BEB of women. This inference is based on the study of the differentiation of factors by the "bass-ackwards" method and would not be made possible if the structure had not been studied sequentially (but rather with targeted EFA factor solutions). Moreover, the finding suggests utility of the "bass-ackwards" in producing conceptually valuable insights into the structure of gender roles. 


\subsection{Descriptive statistics and gender differences for the BEB-M and BEB-W}

Table 5 Descriptive statistics for the BEB-M and BEB-W

\begin{tabular}{llrrrrr}
\hline & Scales & $M$ & \multicolumn{1}{c}{$S D$} & \multicolumn{1}{c}{$S k$} & \multicolumn{1}{c}{$K u$} & $\alpha$ \\
\hline BEB-M & BPowerful & 3.26 & 1.28 & .485 & -.033 & .68 \\
& DGeneralEmotionality & 3.22 & .82 & -.141 & -.039 & .69 \\
& NegattitudeEmotionalBehav & 3.74 & 1.12 & .029 & -.116 & .81 \\
& BPowerless & 2.01 & 1.11 & 1.151 & .934 & .91 \\
\hline BEB-W & BPowerful & 2.76 & 1.36 & .719 & .044 & .77 \\
& DGeneralEmotionality & 4.56 & 1.10 & -.712 & .499 & .82 \\
& NegattitudeEmotionalBehav & 3.10 & .95 & .326 & .146 & .75 \\
& BPowerless & 1.82 & .87 & 1.252 & 1.656 & .88 \\
& DysfEmotionsAtWork & 3.53 & 1.36 & .101 & -.671 & .77 \\
\hline
\end{tabular}

Note. BPowerful - Ban on displaying powerful emotions; DGeneralEmotionality - Description of general emotionality (free of evaluation); NegattitudeEmotionalBehav - Negative attitude towards emotional behaviour; BPowerless - Ban on displaying powerless emotions;

DysfEmotionsAtWork - Dysfuncionality of emotions at work; Sk - skewness; Ku - kurtosis.

$$
\mathrm{N}=247
$$

As we can see in table 5, scores on all examined variables are normally distributed, except Ban on displaying powerless emotions both in BEB-M and BEB-W, which points to the particularly low endorsement rates. However, judging by the SD and kurtosis values it could be interpreted as indicating more uniformity in the responses on this scale in the BEB-W compared to BEB-M. Measures of internal consistency are all satisfactory.

Table 6 Gender differences on BEB-M and BEB-W scales

\begin{tabular}{|c|c|c|c|c|c|}
\hline & Scales & Gender & $M$ & $t$ & $p$ \\
\hline \multirow[t]{4}{*}{ BEB-M } & BPowerful & $\begin{array}{l}\text { male } \\
\text { female }\end{array}$ & $\begin{array}{l}3.53 \\
3.04\end{array}$ & 3.00 & .003 \\
\hline & DGeneralEmotionality & $\begin{array}{l}\text { male } \\
\text { female }\end{array}$ & $\begin{array}{l}3.20 \\
3.24\end{array}$ & -.40 & .687 \\
\hline & NegattitudeEmotionalBehav & $\begin{array}{l}\text { male } \\
\text { female }\end{array}$ & $\begin{array}{l}4.13 \\
3.43\end{array}$ & 5.16 & .000 \\
\hline & BPowerless & $\begin{array}{l}\text { male } \\
\text { female }\end{array}$ & $\begin{array}{l}2.49 \\
1.63\end{array}$ & 6.53 & .000 \\
\hline \multirow[t]{5}{*}{ BEB-W } & BPowerful & $\begin{array}{l}\text { male } \\
\text { female }\end{array}$ & $\begin{array}{l}3.15 \\
2.44\end{array}$ & 4.19 & .000 \\
\hline & DGeneralEmotionality & $\begin{array}{l}\text { male } \\
\text { female }\end{array}$ & $\begin{array}{l}4.68 \\
4.46\end{array}$ & 1.53 & .129 \\
\hline & NegattitudeEmotionalBehav & $\begin{array}{l}\text { male } \\
\text { female }\end{array}$ & $\begin{array}{l}3.27 \\
2.96\end{array}$ & 2.64 & .009 \\
\hline & BPowerless & $\begin{array}{l}\text { male } \\
\text { female }\end{array}$ & $\begin{array}{l}1.97 \\
1.70\end{array}$ & 2.44 & .015 \\
\hline & DysfEmotionsAtWork & $\begin{array}{l}\text { male } \\
\text { female }\end{array}$ & $\begin{array}{l}3.82 \\
3.30\end{array}$ & 3.02 & .003 \\
\hline
\end{tabular}

Note. BPowerful - Ban on displaying powerful emotions; DGeneralEmotionality - Description of general emotionality (free of evaluation); NegattitudeEmotionalBehav - Negative attitude towards emotional behaviour; BPowerless - Ban on displaying powerless emotions; DysfEmotionsAtWork -

Dysfuncionality of emotions at work.

$$
\mathrm{N}=247
$$


Table 6 shows that on average men endorse beliefs about emotional behaviour across scales more than women, pointing to more generalized perceptions of emotional behavior (stereotypical in a generic sense) based on the information about gender of the subject in men. However, the finding needs replication in order to provide further evidence that would allow for a sounder interpretation of the differences presented here.

\section{DISCUSSION}

Although many previous studies have shown that differences in norms regarding male and female emotional behaviour exist (Fischer \& Manstead 2000; Hess et al. 2000; Plant et al. 2000; Timmers et al. 2003), studies such as these have not been conducted in Serbia. Hofstede et al. (2010) highlight that cultures differ in the level of differentiation between male and female roles, as well as in the expectations placed on individual members to conform to specific cultural norms. Therefore, a systematic psychological investigation of norms pertaining to the emotional behaviour of men and women was deemed a significant problem, whose solution required an adequate instrument. We decided to use an instrument offered by Timmers et al. (2003) and adapt (reconstruct) it on a sample of Serbian students.

These cross-cultural differences are particularly relevant for the constructs investigated in this study and therefore it is necessary to take them into account during cross-cultural adaptation of psychological measuring instruments (Hedrih 2018). When compared using Hofstede's dimensions, the Netherlands (the country in which the original study by Timmers et al. was conducted) ranks low on the Power Distance dimension, is predominantly individualist, feminine, indulgent society, and has a slight preference for avoiding uncertainty and a pragmatic orientation (Hofstede et al. 2010), while Serbia ranks high on power distance, is collectivistic, relatively feminine, restrained society, with a high preference for avoiding uncertainty and no preference on the Long Term Orientation scale. Despite the differences between the two cultures, with regards to dimensions pertaining to gender roles and emotional behaviour, the structure of the BEB is largely replicated both in the context of social norms in our society and beliefs regulating masculine and feminine behaviour. Differences exist in the way in which the constructs function, that is, in the way in which they are manifested in social and psychological reality. Still, the similarities in the anticipated and realized structure of both constructs strongly support the notion that they exist in both cultures.

It was decided that the beliefs regarding the emotional behaviour of men would be examined using an instrument separate from the one examining the emotional behaviour of women. Additionally, the initial set of items was supplemented by items targeting beliefs pertaining to manifestations of surprise, disgust and contempt, in line with Ekman's model of basic emotions (1999a; 1999b). Through the application of an exploratory sequentialfactor analysis latent structures of the instruments Beliefs about men's emotional behaviour $(B E B-M)$ and Beliefs about women's emotional behaviour (BEB-W) were obtained. Despite these differences, items usually scattered in line with the schema predicted by Timmers et al. (2003), which is itself based on the distinctions between contra-stereotypical and stereotypical, as well as between prescriptive and descriptive. With regards to the BEB-M instrument, the decision to use a four-factor solution was based on interpretability, as well as the results of parallel analysis (Horn, 1965) and the MAP procedure (Velicer 1976). The following factors were identified: Negative attitudes towards emotional behaviour, which make up a large part of stereotypical descriptive beliefs; Ban on displaying powerless 
emotions, which predominantly attracts stereotypical prescriptive beliefs; Ban on displaying powerful emotions, which attracts contra-stereotypical prescriptive beliefs, and Description of general emotionality (free of evaluation), consists mostly of contra-stereotypical descriptive beliefs.

When it comes to the BEB-W instrument, this study employed a five-factor solution; although a four-factor solution, suggested by parallel analysis (Horn 1965) and supported by the MAP procedure (Velicer 1976), can be considered acceptable. On the final level of hierarchy, the following factors were identified: Description of general emotionality (free of evaluation), predominantly composed of stereotypical descriptive beliefs; Dysfunctionality of emotions at work, consisting primarily of contra-stereotypical descriptive beliefs referring to emotional behaviour at work; Negative attitudes towards emotional behaviour, predominantly composed of contra-stereotypical descriptive beliefs; Ban on displaying powerful emotions, which primarily attracts stereotypical prescriptive beliefs, and Ban on displaying powerless emotions, composed primarily of contra-stereotypical prescriptive beliefs.

We opted to abandon a stereotypical - contra-stereotypical distinction, and instead chose to name the factors according to the content in order to allow for less culturally biased conception of emotional behaviour in the context of gender roles. This would allow for the factor with corresponding content in different item sets (or samples) to be given the same name, thus facilitating comparison between gender roles and cultures alike.

Therefore, the factor structures of both instruments are mostly symmetrical (in a descriptive sense). One important difference, however, is found in the fact that beliefs concerning the dysfunctionality of emotions at work do not stand within a separate factor in the structure of norms concerning male emotional behaviour, as opposed to those concerning female. Instead, the beliefs related to the standards about the men's emotional regulation at work are united with the norms about the emotional regulation marked with vulnerability (sentimentality, non-restraint, and the tendency to cry) without any context. It could be concluded that a women's emotional regulation during business communication is a subject of a consistent group of norms that govern it. Pettigrew and Meertens (1995) point out the tendency towards the formation of 'ideological clusters of beliefs' as an important feature of stereotypes. This is to draw attention to the importance of the principles of joining beliefs into clusters (and also differentiating between clusters of different beliefs). With this in mind, the findings may suggest that women's control of emotions in a work-related context has an important role regardless of their conduct elsewhere, which is probably rooted in public opinion about women's behaviour at work. This is probably derived from demographic changes that come from higher inclusion of women on the job market, as well as the insufficient division of work in the household (Republican Bureau of Statistics, 2012). Problems facing women in leadership position related to emotional expressivity were a point of focus for Victoria Brescoll (2016). She highlighted that female, but not male, leaders can be penalized for displays of emotion, especially when the emotion conveys dominance (e.g. anger or pride), but also for being emotionally unexpressive, because unemotional women are seen as insufficiently communal, which is a female role proposed by gender stereotypes.

The finding that the item referring to the ban on manifestations of jealousy in the BEB-M instrument, besides loading the Negative attitudes towards emotional behaviour factor, also loaded a factor attracting markers of emotions of power might indicate that male manifestations of jealousy are stereotypically tied to manifestations of force. Having in mind that emotions of power (e.g. anger) in different cultures is commonly tied to the 
male gender role (Hess et. al. 2000; Plant et al. 2000; Timmers et al. 2003), it is possible that distress, caused by jealousy, manifests itself differently in men and women, in accordance with general gender stereotypes. This could possibly provide an explanation as to why this item in BEB-M is loaded with the factor Ban on displaying powerful emotions, while in the case of BEB-W it is loaded with the factor Negative attitudes towards emotional behaviour, which refers to an attitude towards increased emotionality of women in general. In other words, manifestations of the same emotion have different meanings in the context of different gender roles (factor structures) and the difference itself is probably tied with the social meaning that an emotion attains when it is manifested by a man (danger) and woman (vulnerability).

Scales Description of general emotionality (free of evaluation) in BEB-M and BEB$\mathrm{W}$ differ from other scales in their formulation - these factors are loaded by items containing direct comparisons between emotional behaviour of men and women. Because of this, these subscales allow for a more direct examination of gender stereotypes and differences in gender norms concerning the emotional behaviour of men and women.

\section{Limitations}

One of the limitations of the study primarily lies in the fact that the sample consists exclusively of students, which are thought to be a "globalized" group of respondents (Hedrih, 2018). Furthermore, the majority of students are studying in the field of social sciences and humanities, who are exposed to certain ideological pressure that would require them not to endorse attitudes that could be taken to be defamatory toward an outgroup. However, the original research of Timmers et al. also used the predominantly student samples for the development. On the other hand, the latent structure is a result of making patterns out of covariation of beliefs and not the absolute levels of endorsements. Therefore, we primarily aimed at inspecting the clustering of beliefs and their meaning (guided by the idea that the clustering is guided by ideological reasons).

In the same vein, another limitation, in the comparison process between the expected and observed belief structure pertaining to emotional behaviour, lies in the fact that the expected (theoretical) structure was not construct validated in Netherlands ${ }^{10}$ rendering any conclusions about the potential effects of culture on the examined constructs merely provisional.

Finally, we did not examine the convergent/discriminant validity of the BEB measures and hence we are not able to discuss the distinctiveness of the concept as it relates to other perhaps similar concepts.

For the purpose of additional verification (and further invariance testing) of the presented latent structure, subsequent research will be focused on comparing structures of instruments given to a subsample consisting of male and a subsample consisting of female respondents.

\footnotetext{
${ }^{10}$ To the best of our knowledge.
} 


\section{CONCLUSION}

The study presented here could be construed as a part of an overall testing of feasibility of questionnaire-based measurement of the stereotypes that refer to emotional behaviour of men and women (as opposed to other potential measurement paradigms such as experimental; and as opposed to other types of stereotypical gender beliefs). This questionnaire based measurement was studied with Goldberg's trait-tier, "bass-ackwards" method and we showed the utility of this method to provide potential insights into the constructs relevant to social psychology.

\section{REFERENCES}

Baumeister, Roy F., \& Brad J. Bushman. Social Psychology and Human Nature (2nd Edition). San Francisco, CA, US: Cengage, 2011.

Benetti-McQuoid, Jessica, and Krisanne Bursik. "Individual Differences in Experiences of and Responses to Guilt and Shame: Examining the Lenses of Gender and Gender Role". Sex Roles 53, 1-2 (2005): 133-142. Accessed February 23, 2019. doi: 10.1007/s11199-005-4287-4.

Blagojević Hughson, Marina. Rodni barometar u Srbiji: razvoj i svakodnevni život. Beograd: Program Ujedinjenih nacija za razvoj, 2013.

Brescoll, Victoria L. "Leading with their Hearts? How Gender Stereotypes of Emotion Lead to Biased Evaluations of Female Leaders". The Leadership Quarterly 27, 3 (2016): 415-428. Accessed March 20, 2019. doi: 10.1016/j.leaqua.2016.02.005.

Caron, P-O. "Minimum Average Partial Correlation and Parallel Analysis: The Influence of Oblique Structures". Communications in Statistics-Simulation and Computation (2018): 1-8. Accessed May 27, 2019. doi: 10.1080/03610918.2018.1433843.

Casey, Rita J., and Laura L. Fuller. "Maternal Regulation of Children's Emotions". Journal of Nonverbal Behavior 18, 1 (1994): 57-89. Accessed February 25, 2019. doi: 10.1007/BF02169079.

Chaplin, Tara M., Pamela M. Cole, and Carolyn Zahn-Waxler. "Parental Socialization of Emotion Expression: Gender Differences and Relations to Child Adjustment". Emotion 5, 1 (2005): 80-88. Accessed February 25, 2019. doi: 10.1037/1528-3542.5.1.80.

Chapman, Benjamin P., Alexander Weiss, Paul Barrett, and Paul Duberstein. "Hierarchical Structure of the Eysenck Personality Inventory in a Large Population Sample: Goldberg's Trait-tier Mapping Procedure". Personality and Individual Differences 54, 4 (2013): 479-484. Accessed May 27, 2019. doi: 10.1016/j.paid. 2012.09.024.

Coats, Erik J., and Robert S. Feldman. "Gender Differences in Nonverbal Correlates of Social Status". Personality and Social Psychology Bulletin 22, 10 (1996): 1014-1022. Accessed February 27, 2019. doi: $10.1177 / 01461672962210004$.

Diener, Marissa L., and Richard E. Lucas. "Adults Desires for Childrens Emotions across 48 Countries: Associations with Individual and National Characteristics". Journal of Cross-cultural Psychology 35, 5 (2004): 525-547. Accessed February 25, 2019. doi: 10.1177/0022022104268387.

Dimberg, Ulf, and Lars-Olov Lundquist. "Gender Differences in Facial Reactions to Facial Expressions". Biological Psychology 30, 2 (1990): 151-159. Accessed February 6, 2019. doi: 10.1016/0301-0511(90)90024-Q.

Ekman, Paul. "Basic Emotions". In Handbook of Cognition and Emotion, edited by Tim Dalgleish, and Mick Power, 45-60. Sussex, U.K.: John Wiley \& Sons, Ltd., 1999a.

Ekman, Paul. "Facial Expressions". In Handbook of Cognition and Emotion, edited by Tim Dalgleish, and Mick Power, 301-320. Sussex, U.K.: John Wiley \& Sons, Ltd., 1999b.

Ferguson, Tamara J., Heidi L. Eyre, and Michael Ashbaker. "Unwanted Identities: A Key Variable in Shameanger Links and Gender Differences in Shame". Sex Roles 42, 3-4 (2000): 133-157. Accessed February 23, 2019. doi: 10.1023/A:1007061505251.

Fischer, Agneta H., and Antony SR Manstead. "The Relation between Gender and Emotions in Different Cultures." In Studies in Emotion and Social Interaction. Second Series. Gender and Emotion: Social Psychological Perspectives, edited by Agneta H. Fischer, 71-94. New York, NY, US: Cambridge University Press, 2000.

Forbes, Miriam K., Roman Kotov, Camilo J. Ruggero, David Watson, Mark Zimmerman, and Robert F. Krueger. "Delineating the Joint Hierarchical Structure of Clinical and Personality Disorders in an 
Outpatient Psychiatric Sample." Comprehensive Psychiatry 79 (2017): 19-30. Accessed May 27, 2019. doi: 10.1016/j.comppsych.2017.04.006.

Goldberg, Lewis R. "Doing it all Bass-ackwards: The Development of Hierarchical Factor Structures from the Top Down." Journal of Research in Personality 40, 4 (2006): 347-358. Accessed March 3, 2019. doi: 10.1016/j.jrp.2006.01.001.

Gorsuch, Richard. "Factor Analysis". In Research Methods in Psychology, edited by John A. Schinka, Wayne F. Velicer, and Irving B. Weiner, 143-164. New Jersey, NY, US: Wiley, 2003.

Havelka, Nenad. Socijalna percepcija. Beograd: Zavod za udžbenike, 2012.

Hedrih, Vladimir. Kroskulturna adaptacija psiholoških mernih instrumenata. Niš: Filozofski fakultet, 2018.

Hess, Ursula, Sacha Senecal, Gilles Kirouac, Pedro Herrera, Pierre Philippot, and Robert E. Kleck. "Emotional Expressivity in Men and Women: Stereotypes and Self-perceptions." Cognition \& Emotion 14, 5 (2000): 609-642. Accessed February 22, 2019. doi: 10.1080/02699930050117648.

Hofstede, Geert, Gert Jan Hofstede, and Michael Minkov. Cultures and Organizations: Software of the Mind (3rd Edition). New York: McGraw-Hill, 2010.

Horn, John L. "A Rationale and Test for the Number of Factors in Factor Analysis". Psychometrika 30, 2 (1965): 179-185. Accessed March 15, 2019. doi: 10.1007/BF02289447.

Huang, Hsin-Yu. "Gender Differences in Facial Expressions of Emotions". PhD diss., Humboldt State University, 2009.

LaFrance, Marianne, Marvin A. Hecht, and Elizabeth Levy Paluck. "The Contingent Smile: A Meta-analysis of Sex Differences in Smiling". Psychological Bulletin 129, 2 (2003): 305. Accessed February 6, 2019. doi: 10.1037/0033-2909.129.2.305.

Loehlin, John C., and Lewis R. Goldberg. "Do Personality Traits Conform to Lists or Hierarchies?". Personality and Individual Differences 70 (2014a): 51-56. Accessed March 3, 2019. doi: 10.1016/j.paid.2014.06.018.

Loehlin, John C., and Lewis R. Goldberg. "How Much is Personality Structure Affected if one or More Highestlevel Factors are First Removed? A Sequential Factors Approach". Personality and Individual Differences 70 (2014b): 176-182. Accessed March 3, 2019. doi: 10.1016/j.paid.2014.06.047

Matsumoto, David, Sachiko Takeuchi, Sari Andayani, Natalia Kouznetsova, and Deborah Krupp. "The Contribution of Individualism vs. Collectivism to Cross-national Differences in Display Rules." Asian Journal of Social Psychology 1, 2 (1998): 147-165. Accessed February 6, 2019. doi: 10.1111/1467839X.00010.

Oatley, W. Keith, and Jennifer M. Jenkins. Understanding Emotions. Oxford, UK: Blackwell Publishers Ltd., 1998.

O'Connor, Brian P. "SPSS and SAS Programs for Determining the Number of Components Using Parallel Analysis and Velicer's MAP Test". Behavior Research Methods, Instruments, \& Computers 32, 3 (2000): 396-402. Accessed March 15, 2019. doi: 10.3758/BF03200807.

Pettigrew, Thomas F., and Roel W. Meertens. "Subtle and Blatant Prejudice in Western Europe". European Journal of Social Psychology 25, 1 (1995): 57-75. Accessed March 2, 2019. doi: 10.1002/ejsp.2420250106.

Plant, E. Ashby, Janet S. Hyde, Dacher Keltner, and Patricia G. Devine. "The Gender Stereotyping of Emotions". Psychology of Women Quarterly 24, 1 (2000): 81-92. Accessed February 7, 2019. doi: 10.1111/j.1471-6402.2000.tb01024.x.

Republički zavod za statistiku Republike Srbije. Korišćenje vremena u Republici Srbiji, 2010/2011. Beograd: Republički zavod za statistiku, 2012.

Rot, Nikola. Osnovi socijalne psihologije. Beograd: Zavod za udžbenike, 2008.

Simon, Robin W., and Leda E. Nath. "Gender and Emotion in the United States: Do Men and Women Differ in Self-reports of Feelings and Expressive Behavior? ". American Journal of Sociology 109, 5 (2004): 11371176. Accessed February 10, 2019. doi: 0002-9602/2004/10905-0004\$10.00.

Timmers, Monique, Agneta Fischer, and Antony Manstead. "Ability versus Vulnerability: Beliefs about Men's and Women's Emotional Behaviour". Cognition and Emotion 17, 1 (2003): 41-63. Accessed October 10, 2018. doi: 10.1080/02699930302277.

Velicer, Wayne F. "Determining the Number of Components from the Matrix of Partial Correlations". Psychometrika 41, 3 (1976): 321-327. Accessed March 15, 2019. doi: 10.1007/BF02293557.

Wood, James M., Douglas J. Tataryn, and Richard L. Gorsuch. "Effects of Under-and Overextraction on Principal Axis Factor Analysis with Varimax Rotation." Psychological methods 1, 4 (1996): 354. Accessed May 27, 2019. doi: 10.1037/1082-989X.1.4.354. 


\section{LATENTNA STRUKTURA VEROVANJA O EMOCIONALNOM PONAŠANJU MUŠKARACA I ŽENA NA UZORKU SRPSKIH STUDENATA: PSIHOMETRIJSKA (RE)EVALUACIJA UPITNIKA O POLNO SPECIFIČNIM VEROVANJIMA}

Pravila koja se odnose na pokazivanje emocija (te i njihove regulacije) određeno društvo propisuje kako bi ponašanje pojedinca usmerilo ka onom koje smatra poželjnim za pripadnika određenog pola. Cilj ovog istraživanja bio je adaptacija (rekonstrukcija) Upitnika polno specifičnih verovanja o emocionalnom ponašanju (Timmers, Fischer, \& Manstead 2003), dopunjenog dodatnim ajtemima, na uzorku srpskih studenata. Veliki broj opserviranih verovanja o stvarnom ili poželjnom emocionalnom ponašanju, u kontekstu odvojenih muških $i$ ženskih polnih uloga, podvrgnut je sekvencijalnoj faktorskoj analizi (Goldbergova ,bass-ackwards“ metoda). Cilj je bio rasvetljavanje specifičnih homogenih skupina verovanja (faktora) $i$ njihovih širih konteksta (faktora višeg reda), te pružanje informacije o tome kako društvo gleda na polne uloge, kao i na potencijalno različite kroskulturne manifestacije navedenih konstrukata. Konačno, evaluirana su dva merna instrumenta, koja su predložena za buduća istraživanja. Psihometrijske karakteristike ovih instrumenata, Verovanja o emocionalnom ponašanju muškaraca (VEP-M) $i$ Verovanja o emocionalnom ponašanju žena (VEP-Ž), procenjene su na osnovu odgovora 247 ispitanika. Na osnovu interpretabilnosti, kao i rezultata paralelne analize i MAP procedure, doneta je odluka da se za instrument VEP-M primeni četvorofaktorsko rešenje, a za VEP-Ž petofaktorsko rešenje.

Ključne reči: polne uloge, emocionalno ponašanje, latentna struktura, sekvencijalni faktori, kroskulturna adaptacija. 